\section{OTS delay}

Last week it was announced that the launch of the European Space Agency's (ESA) orbital test satellite (OTS), designed for experiments in communications, would not go ahead as scheduled next month because of damage to the American Delta 3914 launch vehicle. In April, ESA's geostationary scientific satellite, Geos, was thrown into a wrong orbit because the Delta 2914 rocket which launched it failed to separate according to plan.

The launch of OTS had already been delayed by the enquiry into the mishap over Geos. The damage to the Delta 3914 occurred when one of the nine solid fuel booster rockets attached to the launcher base fell off, damaging the rocket's first stage. The rescheduled launch date is 8 September; the Meteosat satellite, which was to have been launched on 15 September, has also been rescheduled, for 3 November. ESA decided that it was prefer- able to delay both satellites by a few months.

\section{OTA director resigns}

Emilio Daddario, the first and only director of the Congressional Office of Technology Assessment (OTA), submitted his resignation last week. In a letter to Senator Edward Kennedy, chairman of the joint committee that controls OTA, Daddario noted that the fledgling office has now completed several major studies and he pointed out that he had long expressed a desire to leave as soon as OTA was firmly established. Established four years ago to provide advice to Congress on technical issues, OTA has encountered a difficult problem in giving long term advice to a body whose attention span is largely governed by the two-year election cycle. It has had a mixed reception and last month Kennedy asked the OTA's Independent Advisory Committee to con- duct a thorough analysis of the office's role and operations. There have been rumours that Kennedy initiated the study and engineered Daddario's resignation as a prelude to taking firm control of OTA. Such rumours were rife when OTA was first established and Kennedy was made chairman of its Congressional board, but they have since proved groundless.

\section{SRC support for AGT}

The UK Science Research Council (SRC) is to increase its support for basic research relating to Advanced Ground Transport (AGT). A UK government White Paper released last week says the SRC hopes to spend up to $£ 200,000$ a year, concentrated mainly in the universities. This is more than the sum that the SRC has spent altogether over the past three years, but will be less than that spent from all sources over the period 1973-76; this totalled over $£ 1$ million.
AN elderly visitor carrying baggage to his bedroom in the usual porterless hotel in modern Britain is likely to suffer at least minor abrasions as he wrestles with the heavily sprung fire doors which obstruct the corridors every few yards. The cost of installing these precautions has meant that hotel charges have risen much more rapidly than inflation alone would have dictated, and many cheaper hotels have closed.

It is right that we should try to make all our activities safe, and new laws may sometimes be required. There have been tragic hotel fires, some buildings are unnecessarily dangerous, but many modifications serve little purpose except to make work for inspectors and builders. The British Health and Safety at Work Act of 1974 contains useful provisions, but its application to laboratories is often governed by dogma rather than commonsense. Precautions, costly in time and money, are taken against the most unlikely catastrophes. Little research has been done to identify the probable dangers in different types of laboratory, where quite different work is done. Our Research Councils must be spending more than $£ 2$ million a year, out of their meagre funds, on 'safety'.

This is all part of the 'nannying' to which we are increasingly subjected. We see those who spend their holidays rockclimbing or even in that most dangerous of sports-motorcycling -insisting on following quite different rules when at work. The various admirable and tough outdoor activities for young people described in his broadcast by the Prince of Wales, and to be supported by the Queen's Jubilee Appeal, will surely

\section{Dangers of safety}

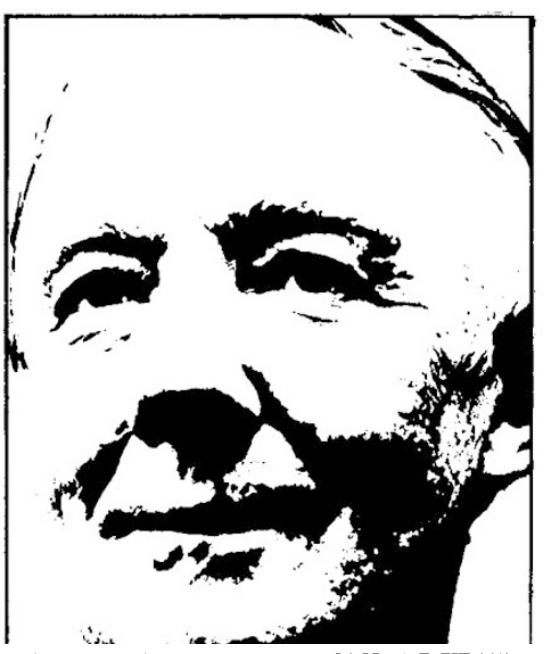

KENNETH MELLANBY

be regulated out of existence.

$I$ find most ludicrous the proposals to set up working parties to draft codes of practice for field work. Field work covers many different activities, some of which may be dangerous, and where obvious and well established precautions should be observed. But for the ecologist it is seldom more hazardous than a gentle country walk to observe birds or to pick wild flowers. Those of us who have done this sort of work should be grateful that someone actually paid us, for many of our less fortunate friends do these things, possibly less systematically, when on holiday. I expect the code will tell us to change our socks if they get damp, and to wrap up well in cold weather. It is unlikely that any joker will be able to produce 'spoof' regulations which will be more absurd than those to be promulgated by the authorities.

We avoided this nonsense in the past because most field work was done almost entirely by responsible scientists themselves, walking on their own feet and observing with their own eyes. Today there is a growing tendency for scientists to remain indoors in their 'offices' and send assistants, admirable workers no doubt, but not personally committed to the investigation, to do the field work. The results of this practice are often, scientifically, disappointing, and it is understandable that the assistants' trade unions should be obsessional about their safety particularly when this increases opportunities for employment.

However, even the best schemes may have unfortunate results. On what was, by coincidence, the first day of European Farm Safety Week an estate worker drove his tractor a little too quickly over a 'sleeping policeman' (a ramp to slow traffic and prevent accidents). He bounced into the air, and hit his head on the roof of his newly-fixed safety cab, so that he had to be taken to hospital to have his scalp stitched. Too many safety precautions can be jolly dangerous. 